\title{
The Effects of Sevelamer and Calcium Acetate on Proxies of Atherosclerotic and Arteriosclerotic Vascular Disease in Hemodialysis Patients
}

\author{
Glenn M. Chertow ${ }^{a}$ Paolo Raggi ${ }^{b}$ James T. McCarthyc Gerald Schulman ${ }^{\mathrm{d}}$ \\ Jeffrey Silberzweige Amy Kuhlik ${ }^{f}$ William G. Goodmang Amy Boulay ${ }^{h}$ \\ Steven K. Burke ${ }^{\text {h Robert D. Toto }}{ }^{\mathrm{i}}$ \\ aDivisions of Nephrology, Moffitt-Long Hospitals and UCSF-Mt. Zion Medical Center, Department of Medicine, \\ University of California San Francisco, San Francisco, Calif., bDivision of Cardiology, Department of Medicine, \\ Tulane University, New Orleans, La., 'Division of Nephrology, Department of Medicine, Mayo Clinic, \\ Rochester, Minn., ${ }^{\mathrm{d} D i v i s i o n}$ of Nephrology, Department of Medicine, Vanderbilt University, Nashville, Tenn., \\ eThe Rogosin Institute and Division of Nephrology, Department of Medicine, Cornell University, New York, N.Y., \\ fDivision of Nephrology, Department of Medicine, Beth Israel Deaconess Medical Center, Boston, Mass., \\ gDivision of Nephrology, Department of Medicine, University of California Los Angeles, Los Angeles, Calif., \\ hGelTex Pharmaceuticals, Inc., Waltham, Mass., and 'Division of Nephrology, Department of Medicine, \\ University of Texas Southwestern Medical Center at Dallas, Dallas, Tex., USA
}

\author{
Key Words \\ Sevelamer · Calcium · Calcification · Arteriosclerosis · \\ Clinical trial
}

\begin{abstract}
Background: We recently determined that in hemodialysis patients, the use of calcium salts to correct hyperphosphatemia led to progressive coronary artery and aortic calcification as determined by sequential electron beam tomography (EBT) while the use of the non-calcium-containing binder sevelamer did not. Whether the specific calcium preparation (acetate vs. carbonate) might influence the likelihood of progressive calcification was debated. Methods: To determine whether treatment with calcium acetate was specifically associated with hypercalcemia and progressive vascular calcification, we conducted an analysis restricted to 108 hemodialysis patients randomized to calcium acetate or seve-
\end{abstract}

lamer and followed for one year. Results: The reduction in serum phosphorus was roughly equivalent with both agents (calcium acetate $-2.5 \pm 1.8 \mathrm{mg} / \mathrm{dl}$ vs. sevelamer $-2.8 \pm 2.0 \mathrm{mg} / \mathrm{dl}, \mathrm{p}=0.53$ ). Subjects given calcium acetate were more likely to develop hypercalcemia (defined as an albumin-corrected serum calcium $\geq 10.5 \mathrm{mg} / \mathrm{dl}$ ) ( 36 vs. $13 \%, p=0.015$ ). Treatment with calcium acetate (mean $4.6 \pm 2.1 \mathrm{~g} /$ day - equivalent to $1.2 \pm 0.5 \mathrm{~g}$ of elemental calcium) led to a significant increase in EBT-determined calcification of the coronary arteries (mean change $182 \pm 350$, median change $+20, p=0.002$ ) and aorta (mean change $181 \pm 855$, median change $+73, p<$ $0.0001)$. These changes were similar in magnitude to those seen with calcium carbonate. There were no significant changes in calcification among sevelamer-treated subjects. Conclusion: Despite purported differences in safety and efficacy relative to calcium carbonate, calcium acetate led to hypercalcemia and progressive vascular calcification in hemodialysis patients.

Copyright $\odot 2003$ S. Karger AG, Base

Glenn M. Chertow, MD, MPH

Department of Medicine Research, University of California San Francisco

UCSF Laurel Heights, Suite 430, 3333 California Street

San Francisco, CA 94118-1211 (USA)

Tel. +1 415476 2173, Fax +1 415476 9531, E-Mail chertowg@medicine.ucsf.edu 


\section{Introduction}

Disorders of mineral metabolism, including hyperphosphatemia, hypercalcemia, and secondary hyperparathyroidism, are frequently seen in advanced stages of chronic kidney disease and have been associated with a significant increase in mortality and morbidity [1-8]. Since the initial reports of the effects of calcium carbonate on phosphate balance [9-11], calcium-based phosphate binders have been widely used to control hyperphosphatemia and hyperparathyroidism in hemodialysis patients $[12,13]$. Noncarbonate salts of calcium, such as calcium acetate, calcium citrate, and calcium ketoglutarate, were collectively applied in an attempt to improve the efficiency of phosphate binding and to reduce the fraction of calcium absorbed [14-17]. Whether or not newer calcium preparations are superior to calcium carbonate remains debatable.

We recently completed a multinational randomized clinical trial [18], in which treatment with calcium-based phosphate binders led to progressive coronary artery and aortic calcification as demonstrated by electron beam tomography (EBT), while treatment with the non-calcium-containing phosphate binder sevelamer did not. In this trial, calcium acetate was employed in the USA and calcium carbonate in Europe. Calcium acetate provides fewer milligram of elemental calcium per tablet than calcium carbonate, and some studies have suggested that calcium acetate may be a more effective phosphate binder $[19,20]$. Indeed, letters to the editor questioned the validity of the study results because of the pooling of results from both calcium preparations [21-24]. To determine whether the overall study findings were uniform across study sites and calcium preparations, we conducted an analysis limited to hemodialysis patients in the USA.

\section{Patients and Methods}

\section{Patients}

We enrolled 108 adult (age $\geq 19$ years) maintenance hemodialysis patients from dialysis units affiliated with seven geographically diverse academic nephrology programs in six states (California, Massachusetts, Minnesota, New York, Tennessee, and Texas). Individuals with the following medical conditions were excluded from participation: serious gastrointestinal disease (including dysphagia, active untreated gastroparesis, severe motility disorder, major intestinal surgery, markedly irregular bowel function), ethanol or drug dependence or abuse, active malignancy, HIV infection, vasculitis, or patients whose diabetes mellitus or hypertension were so poorly controlled as to interfere with the conduct of the study as deemed by the investigator. Written informed consent was obtained from all subjects. The study was conducted in compliance with the Declaration of Helsinki and Committees on Human Research at each of the participating universities and dialysis units.

\section{Study Design and Procedures}

Washout (Run-In) Phase. After screening, the subjects underwent a 2-week washout period during which all phosphate binders were withheld (weeks -2 to 0 ). Subjects who developed hyperphosphatemia (serum phosphorus $>5.5 \mathrm{mg} / \mathrm{dl}$ ) during the washout period were eligible for randomization.

Randomization. Subjects were randomized (computer generated) in a 1:1 ratio to receive either sevelamer or calcium acetate and were stratified by clinical site and the diagnosis of diabetes mellitus at screening.

Treatment Phase. The subjects were randomized to sevelamer (Renage $^{\circledR}$, 800-mg tablets; GelTex Pharmaceuticals, Waltham, Mass., USA) or calcium acetate (PhosLo ${ }^{\circledR}, 667-\mathrm{mg}$ tablets; Braintree Pharmaceuticals, Braintree, Mass., USA). Due to size, appearance, and taste of the tablets, neither the subjects nor the Investigators were blinded. Adherence to treatment was verified by pill counts.

The treatment phase lasted 52 weeks. During the first 12 weeks, the dose of the phosphate binder was titrated every 3 weeks to achieve serum phosphorus and calcium concentrations in the target ranges of 3.0-5.0 and $8.5-10.5 \mathrm{mg} / \mathrm{dl}$, respectively. Serum calcium was adjusted for the serum albumin concentration using the formula: adjusted $\mathrm{Ca}=$ [total measured calcium $+0.8 \times(4.0-$ albumin $\mathrm{g} / \mathrm{dl})]$. Hypercalcemia was defined as albumin-adjusted calcium $\geq 10.5 \mathrm{mg} /$ dl. The subjects could use aluminum as a rescue binder, if the calcium-phosphorus $(\mathrm{Ca} \times \mathrm{P})$ product exceeded $72 \mathrm{mg}^{2} / \mathrm{dl}^{2}$. After 12 weeks, the doses of phosphate binder and vitamin $\mathrm{D}$ and the dialysate calcium concentration could be titrated every 4 weeks to achieve serum phosphorus and calcium levels in the aforementioned target ranges. The target range for parathyroid hormone (PTH) was 150 $300 \mathrm{pg} / \mathrm{ml}$.

Serum phosphorus and calcium were drawn weekly during the titration phase and monthly thereafter. PTH was determined at screening, baseline, 12 weeks, and monthly thereafter, using an assay that detected 1-84 PTH as well as amino-terminally-truncated fragments (e.g., 7-84 PTH). Total cholesterol, low-density lipoprotein (LDL) cholesterol, LDL particle size, high-density lipoprotein (HDL) cholesterol, triglycerides, apolipoprotein A, and apoliprotein B were drawn at baseline and at 12, 24, and 52 weeks. Homocysteine and highly sensitive C-reactive protein were drawn at baseline and 52 weeks. LDL particle concentration and size were analyzed at Liposciences (Raleigh, N.C., USA). All other blood samples were analyzed at Quest Diagnostics (Van Nuys, Calif., USA). LDL was calculated according to the Friedewald formula on nonfasting samples [25, 26].

Imaging Procedure. The subjects underwent an EBT imaging procedure at day 0 and at 26 and 52 weeks. Details of the methods and reliability of EBT imaging have been published elsewhere [27]. Briefly, all areas of calcification with a minimal density of 130 Hounsfield units within the borders of coronary arteries, thoracic aorta, mitral valve, and aortic valve were computed. The traditional calcium score originally described by Agatston et al. [28] was calculated. The Agatston score is obtained by multiplying the area of a calcified focus by a weighted density coefficient based on the peak density measured inside the calcified focus. The median interscan variability for the Agatston score is $8-10 \%$ [27]. Scans were considered of acceptable research quality only if the images were free from artifacts due to 
Table 1. Baseline characteristics of the study subjects

\begin{tabular}{|c|c|c|c|}
\hline & $\begin{array}{l}\text { Sevelamer } \\
(\mathrm{n}=54)\end{array}$ & $\begin{array}{l}\text { Calcium acetate } \\
(\mathrm{n}=54)\end{array}$ & $\mathrm{p}$ \\
\hline Age, years (mean $\pm \mathrm{SD})$ & $58 \pm 15$ & $54 \pm 17$ & 0.25 \\
\hline Sex, n (\% females) & $22(41)$ & $16(30)$ & 0.31 \\
\hline Race, n (\% black) & $17(32)$ & $22(41)$ & 0.33 \\
\hline Diabetes, n (\%) & $25(46)$ & $23(43)$ & 0.85 \\
\hline \multicolumn{4}{|l|}{ Time on dialysis, months; median } \\
\hline Body mass index, $\mathrm{kg} / \mathrm{m}^{2}($ mean $\pm \mathrm{SD})$ & $25.8 \pm 3.9$ & $26.6 \pm 5.3$ & 0.47 \\
\hline \multicolumn{4}{|l|}{ Primary cause of end-stage renal disease, $\mathrm{n}(\%)$} \\
\hline Diabetes & $19(35)$ & $20(37)$ & 0.97 \\
\hline Hypertension & $11(20)$ & $13(24)$ & \\
\hline Glomerulonephritis & $7(13)$ & $8(15)$ & \\
\hline Polycystic kidney disease & $2(4)$ & $1(2)$ & \\
\hline Interstitial nephritis & $1(2)$ & $0(0)$ & \\
\hline Other & $14(26)$ & $12(22)$ & \\
\hline Systolic blood pressure, $\mathrm{mm} \mathrm{Hg}($ mean $\pm \mathrm{SD})$ & $139 \pm 21$ & $146 \pm 24$ & 0.11 \\
\hline Diastolic blood pressure, $\mathrm{mm} \mathrm{Hg}($ mean $\pm \mathrm{SD})$ & $76 \pm 12$ & $79 \pm 12$ & 0.13 \\
\hline $\begin{array}{l}\text { Coronary artery Agatston score, median } \\
\text { (interquartile range) }\end{array}$ & $570(1-1,909)$ & $506(45-1,084)$ & 0.57 \\
\hline $\begin{array}{l}\text { Aortic Agatston score, median } \\
\quad \text { (interquartile range) }\end{array}$ & $349(25-2,516)$ & $190(0-1,379)$ & 0.23 \\
\hline \multicolumn{4}{|l|}{ Current phosphate binder, n (\%) } \\
\hline Calcium acetate & $24(44)$ & $24(44)$ & 0.86 \\
\hline Calcium carbonate & $22(41)$ & $25(46)$ & \\
\hline Sevelamer & $3(6)$ & $1(2)$ & \\
\hline Calcium carbonate with sevelamer & $2(4)$ & $1(2)$ & \\
\hline Calcium acetate with sevelamer & $2(4)$ & $2(4)$ & \\
\hline Other & $1(2)$ & $1(2)$ & \\
\hline Current smoking, n (\%) & $1(2)$ & $2(4)$ & 0.85 \\
\hline History of kidney transplantation, n (\%) & $10(19)$ & $10(19)$ & 1.00 \\
\hline History of parathyroidectomy, $\mathrm{n}(\%)$ & $5(9)$ & $1(2)$ & 0.21 \\
\hline Vitamin D usage, $\mathrm{n}(\%)$ & $33(61)$ & $32(59)$ & 1.00 \\
\hline $\begin{array}{l}\text { Use of HMG-CoA reductase inhibitors } \\
\text { ('statins'), } \mathrm{n}(\%)\end{array}$ & $10(19)$ & $18(33)$ & 0.12 \\
\hline
\end{tabular}

motion, respiration, or asynchronous electrocardiographic triggering.

\section{Statistics}

Continuous variables were expressed as mean \pm SD or median \pm interquartile range. Within-group comparisons were made with the Wilcoxon signed-rank test. Between-group comparisons were made either with Student's $t$ test or with the Wilcoxon rank sum test where appropriate. Categorical variables were compared with Fisher's exact test. Laboratory data were analyzed after employing a last value carried forward procedure. For subjects who underwent EBT at week 52 , the changes in calcification were calculated by subtracting the week 52 scores from baseline scores. Nonparametric inference testing was applied to EBT data to provide conservative $\mathrm{p}$ value estimates. The overall study was powered $(1-\beta=0.9)$ to achieve a $10-\mathrm{mg}^{2} / \mathrm{dl}^{2}$ difference in the calcium-phosphorus product. The power to demonstrate differences in EBT scores was unknown at the time the study was designed, as the standard deviation of change in EBT score in end-stage renal disease was unknown. We a priori planned a subgroup analysis of sevelamer versus calcium acetate. All reported $\mathrm{p}$ values are two tailed. $\mathrm{p}<0.05$ was considered statistically significant. Analyses were conducted using SAS 8.02 (SAS Institute, Cary, N.C., USA).

\section{Results}

\section{Comparing US with European Subjects}

To determine whether there were significant differences among the study subjects by geographic region (aside from the prescribed calcium salt), we compared demographic factors and baseline EBT scores in US and European subjects. There was no difference in mean age $(55.9 \pm 16.0$ vs. $56.9 \pm 13.7$ years, $\mathrm{p}=0.63)$ or in the proportion of women (35 vs. $34 \%, p=0.96)$. Subjects in the USA were significantly more likely to be black (37 vs. $1 \%, \mathrm{p}<0.0001$ ), to have diabetes mellitus ( 44 vs. $18 \%, \mathrm{p}=$ 
Table 2. Biochemical end points

\begin{tabular}{|c|c|c|c|c|c|}
\hline & \multicolumn{2}{|l|}{ Sevelamer } & \multicolumn{2}{|l|}{ Calcium } & \multirow[t]{2}{*}{$\mathrm{p}$} \\
\hline & baseline & final & baseline & final & \\
\hline Phosphorus, mg/dl & $7.6 \pm 1.9$ & $4.9 \pm 1.2$ & $7.7 \pm 2.1$ & $5.0 \pm 1.5$ & 0.53 \\
\hline Calcium, mg/dl & $9.4 \pm 0.7$ & $9.5 \pm 0.7$ & $9.4 \pm 0.7$ & $9.6 \pm 0.6$ & 0.39 \\
\hline Calcium-phosphorus product, $\mathrm{mg}^{2} / \mathrm{dl}^{2}$ & $71 \pm 19$ & $47 \pm 13$ & $72 \pm 20$ & $48 \pm 15$ & 0.59 \\
\hline Intact PTH, $\mathrm{pg} / \mathrm{ml}$ & $232(159-359)$ & $180(123-284)$ & $215(148-320)$ & $161(78-262)$ & 0.60 \\
\hline Total cholesterol, mg/dl & $167 \pm 31$ & $135 \pm 32$ & $171 \pm 43$ & $175 \pm 49$ & $<0.0001$ \\
\hline LDL cholesterol, mg/dl & $96 \pm 24$ & $64 \pm 20$ & $93 \pm 37$ & $97 \pm 44$ & $<0.0001$ \\
\hline HDL cholesterol, mg/dl & $41.8 \pm 10.6$ & $43.1 \pm 10.8$ & $44.6 \pm 16.7$ & $44.2 \pm 12.3$ & 0.03 \\
\hline Triglycerides, mg/dl & $117(94-171)$ & $102(75-188)$ & $132(84-203)$ & $147(99-221)$ & 0.44 \\
\hline Highly sensitive C-reactive protein, $\mathrm{mg} / \mathrm{l}$ & $7.0(2.3-22.8)$ & $3.3(1.2-9.7)$ & $6.4(1.8-10.4)$ & $4.3(1.6-17.4)$ & 0.014 \\
\hline Apolipoprotein A1, mg/l & $110 \pm 16$ & $112 \pm 17$ & $111 \pm 16$ & $109 \pm 16$ & 0.28 \\
\hline Apolipoprotein B, mg/l & $78 \pm 18$ & $62 \pm 15$ & $78 \pm 25$ & $78 \pm 27$ & $<0.0001$ \\
\hline Lipoprotein A, mg/dl & $31(19-53)$ & $42(12-39)$ & $36(16-51)$ & $42(26-49)$ & 0.25 \\
\hline Homocysteine, $\mu \mathrm{mol} / 1$ & $21(17-27)$ & $23(18-25)$ & $22(19-24)$ & $23(21-29)$ & 0.79 \\
\hline LDL particles, nmol/1 & $907 \pm 252$ & $749 \pm 242$ & $960 \pm 290$ & $958 \pm 309$ & 0.011 \\
\hline LDL particle size, $\mathrm{nm}$ & $21 \pm 0.6$ & $21 \pm 0.6$ & $21 \pm 0.6$ & $21 \pm 0.6$ & 0.70 \\
\hline
\end{tabular}

Values are expressed as mean $\pm \mathrm{SD}$, except for intact PTH, triglycerides, highly sensitive C-reactive protein, lipoprotein A, and homocysteine which are expressed as median and interquartile range in parentheses.

0.00014 ), and to have shorter dialysis vintage (median 32 vs. 45 months, $p=0.009$ ) than European subjects. Baseline coronary artery calcification scores [median 508 (interquartile range 17-1,482) vs. $949(184-1,808), \mathrm{p}=$ 0.036 ] and aortic calcification scores [median 253 (interquartile range $2-2,268)$ vs. $1,802(144-6,553), \mathrm{p}=$ $0.0014]$ were significantly lower in US as compared with European subjects.

\section{Baseline Characteristics of US Subjects by Binder Assignment}

The baseline characteristics of the 108 US study subjects by binder assignment are shown in table 1 . The groups were well balanced by randomization. Coronary and aortic calcifications tended to be higher at baseline in the subjects randomized to sevelamer, although the differences were not statistically significant.

\section{Drug Dosing}

The average dose of sevelamer was $6.7 \pm 3.4 \mathrm{~g}$ /day (approximately $8 \pm 4$ tablets), and the average dose of calcium acetate was $4.6 \pm 2.1 \mathrm{~g} /$ day (approximately $7 \pm 3$ tablets). Adherence was very good for both regimens (78\% for sevelamer vs. $73 \%$ for calcium acetate). Vitamin D and vitamin $\mathrm{D}$ analog usage increased over time in the sevelamer-treated subjects (median change 0 , interquartile range $0-3 \mu \mathrm{g}$ calcitriol equivalents) and decreased over time in the calcium-treated subjects (median change 0 , interquartile range -1.5 to $0 \mu \mathrm{g}$ calcitriol equivalents $(p=0.0006)$.

\section{Laboratory Findings}

Mineral Metabolism. Table 2 summarizes the key biochemical end points. Baseline values represent laboratory test results obtained after a 2-week phosphate-binder-free washout period. Sevelamer and calcium acetate yielded a similar reduction in serum phosphorus from baseline to the end-of-study (sevelamer $-2.8 \pm 2.0 \mathrm{mg} / \mathrm{dl}$ vs. calcium acetate $-2.5 \pm 1.8 \mathrm{mg} / \mathrm{dl}, \mathrm{p}=0.53)$. The reduction in the calcium-phosphorus product was likewise similar in both groups (sevelamer $-24.6 \pm 19.9 \mathrm{mg} / \mathrm{dl}$ vs. calcium acetate $-21.0 \pm 18.0 \mathrm{mg} / \mathrm{dl}, \mathrm{p}=0.59)$. While the end-of-study serum calcium concentrations were not significantly different in the two treatment arms, the time-averaged serum calcium concentration was higher in the calciumacetate-treated subjects $(9.6 \pm 0.7$ vs. $9.2 \pm 0.6 \mathrm{mg} / \mathrm{dl}$, $\mathrm{p}=0.003$ ). Calcium acetate was more likely to lead to hypercalcemia ( 36 vs. $13 \%, p=0.015$ ). The frequency of hypercalcemia in the calcium-acetate-treated subjects was attenuated by several factors specified in the protocol for safety considerations. These included a reduction in calcium acetate dosage (if the subject was within the target range for phosphorus), reduction or discontinuation of vitamin $\mathrm{D}$, a reduction in dialysate calcium (documented 
in more than $10 \%$ of the calcium-acetate-treated subjects), and the use of 'rescue' aluminum hydroxide. There was a trend toward lower time-averaged PTH in the calcium-acetate-treated group (median 169, interquartile range $93-276 \mathrm{pg} / \mathrm{ml}$, vs. median 220 , interquartile range 144-280 pg/ml, $\mathrm{p}=0.07)$. Unintended suppression of PTH was more frequent in calcium-acetate-treated subjects. Figure 1 shows the median PTH values for the 38 subjects who had a PTH level $<150 \mathrm{pg} / \mathrm{ml}$ by week 12 . Despite provisions to attenuate hypercalcemia (see above), the median PTH concentration remained well below the 150 - to $300-\mathrm{pg} / \mathrm{ml}$ target range in the calciumacetate-treated subjects, while the median PTH level increased to within target in the sevelamer-treated subjects by week 16 .

Lipids and Markers of Inflammation. The subjects randomized to sevelamer experienced significant reductions in total cholesterol $(-36.7 \pm 27.1 \mathrm{mg} / \mathrm{dl}, \mathrm{p}<0.0001)$, LDL cholesterol $(-39.3 \pm 20.2 \mathrm{mg} / \mathrm{dl}, \mathrm{p}<0.0001), \mathrm{LDL}$ cholesterol particle concentration $(-157 \pm 270 \mathrm{nmol} / \mathrm{l}$, $\mathrm{p}=0.01)$, and apolipoprotein B levels $(-20.0 \pm 13.7 \mathrm{mg} /$ $\mathrm{dl}, \mathrm{p}<0.0001)$. Sevelamer also led to a small but significant increase in HDL cholesterol $(2.1 \pm 7.9 \mathrm{mg} / \mathrm{dl}, \mathrm{p}=$ 0.036). There were no significant changes in triglycerides, apolipoprotein A, or LDL particle size in the sevelamertreated subjects. Calcium acetate had no effect on any lipid parameters. The sevelamer-treated subjects experienced a relative reduction in highly sensitive C-reactive protein as compared with calcium-acetate-treated subjects [median change -2.8 (interquartile range from -13.7 to -0.4$) \mathrm{mg} / \mathrm{l}$ vs. -0.3 (interquartile range from -5.3 to 2.8$) \mathrm{mg} / \mathrm{l}, \mathrm{p}=0.014$ ]. The change in highly sensitive C-reactive protein was not related to baseline values of, or change in, leukocyte count or LDL cholesterol concentration.

\section{EBT Findings}

The baseline vascular calcification was extensive (table 1), as previously reported [29]. Subjects on calcium acetate experienced a significant increase in coronary artery (mean change $182 \pm 350$, median change $+20, \mathrm{p}=$ 0.002 ) and aortic (mean change $181 \pm 855$, median change $+73, \mathrm{p}<0.0001)$ calcification scores by EBT. European subjects experienced a similar magnitude of progression with calcium carbonate (data not shown). There was no evidence of progressive coronary artery (mean change $64 \pm 471$, median change $+4, p=0.18$ ) or aortic (mean change $-127 \pm 942$, median change $+30, p=$ 0.20 ) calcification scores in the sevelamer-treated subjects.

Sevelamer vs. Calcium Acetate

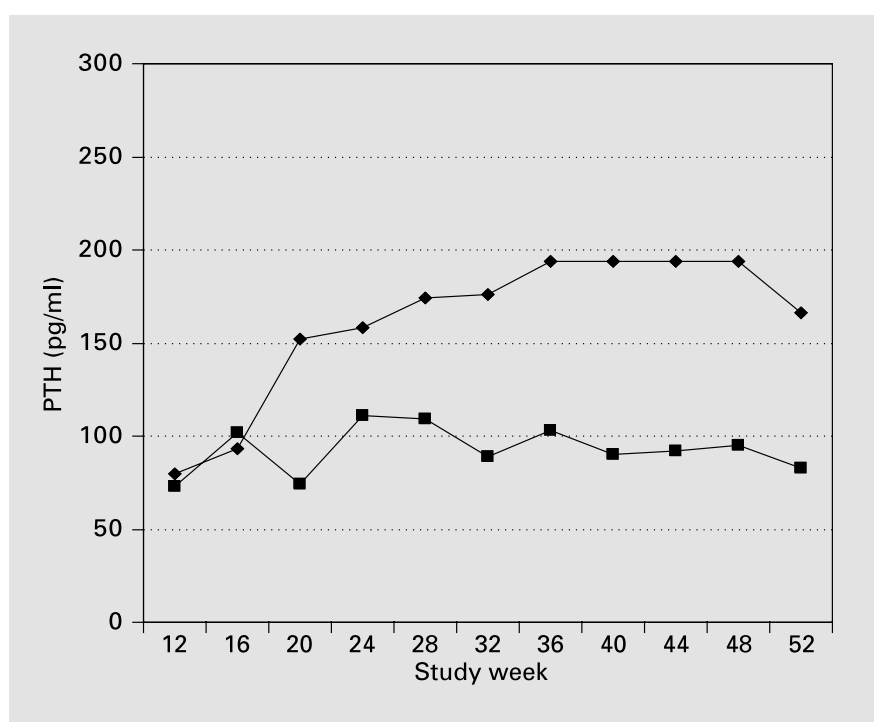

Fig. 1. Trend in PTH among 38 subjects with a week $12 \mathrm{PTH}$ level $<150 \mathrm{pg} / \mathrm{ml} . \mathrm{n}=15$ and $\mathrm{n}=23$ for sevelamer (diamonds) and calcium acetate (squares) groups, respectively.

To allow inclusion of subjects who underwent a 26-week EBT and may not have completed the 52-week study, we also estimated the weekly change in coronary artery and aortic calcification scores. Expressed as a change in calcification scores per week, there was a significant increase in coronary artery (mean change $5.1 \pm 9.3$, median change $+0.6, \mathrm{p}=0.0004$ ) and aortic (mean change $17.9 \pm 66.5$, median change $+1.9, \mathrm{p}<0.0001)$ calcification scores in the calcium-acetate-treated subjects. In contrast, there was no progression in vascular calcification in the sevelamertreated subjects [corresponding mean changes -0.1 and -2.6 and median changes $0(p=0.38)$ and $0.6(p=0.33)$ for coronary arteries and aorta, respectively].

The EBT findings are even more noteworthy when considering that HMG-CoA reductase inhibitors ('statins') were prescribed more frequently in calcium-acetatetreated subjects (46 vs. $22 \%$ of the subjects who had two or more EBT scans, $\mathrm{p}<0.05)$.

\section{Safety}

The adverse drug events observed in $\geq 10 \%$ of the subjects are displayed in table 3.16 of 17 (94\%) adverse drug events were more common in the calcium-acetate-treated subjects, although, when considered individually, only the proportion of subjects with headaches $(20.4$ vs. $3.7 \%$, p = $0.015)$ was significantly different. There was a significant reduction in the end-of-study serum bicarbonate concentrations in the sevelamer-treated subjects $(20.0 \pm 4.6 \mathrm{vs}$. 
Table 3. Adverse events associated with sevelamer and calcium acetate

\begin{tabular}{|c|c|c|c|c|}
\hline \multirow[t]{2}{*}{ Adverse events } & \multicolumn{2}{|c|}{$\begin{array}{l}\text { Sevelamer } \\
(\mathrm{n}=54)\end{array}$} & \multicolumn{2}{|c|}{$\begin{array}{l}\text { Calcium acetate } \\
(\mathrm{n}=54)\end{array}$} \\
\hline & $\mathrm{n}$ & $\%$ & $\mathrm{n}$ & $\%$ \\
\hline Vomiting & 9 & 17 & 14 & 26 \\
\hline Nausea & 10 & 19 & 13 & 24 \\
\hline Diarrhea & 10 & 19 & 13 & 24 \\
\hline Pain in limb & 8 & 15 & 10 & 19 \\
\hline Pruritus & 7 & 13 & 3 & 6 \\
\hline Arthralgia & 7 & 13 & 8 & 15 \\
\hline Dyspnea & 8 & 15 & 10 & 19 \\
\hline Headache* & 2 & 4 & 11 & 20 \\
\hline Constipation & 6 & 11 & 9 & 17 \\
\hline Insomnia & 5 & 9 & 6 & 11 \\
\hline Cough & 5 & 9 & 7 & 13 \\
\hline Chest pain & 4 & 7 & 6 & 11 \\
\hline \multicolumn{5}{|l|}{ Mechanical complication } \\
\hline of implant & 5 & 9 & 8 & 15 \\
\hline \multicolumn{5}{|l|}{ Upper respiratory tract } \\
\hline infection & 5 & 9 & 11 & 20 \\
\hline Hypertension aggravated & 2 & 4 & 8 & 15 \\
\hline
\end{tabular}

$* \mathrm{p}=0.015$, all other comparisons $\mathrm{p}>0.05$

$22.9 \pm 5.0 \mathrm{mEq} / \mathrm{l}, \mathrm{p}=0.0006)$. Twenty $(37 \%)$ sevelamertreated subjects and $26(48 \%)$ calcium-acetate-treated subjects were hospitalized over the course of the study.

\section{Discussion}

Despite the widespread use of phosphate binders in patients with end-stage renal disease, relatively few studies have compared their relative safety and efficacy. Most studies have been small in number (50 subjects or fewer), short term (12 weeks or less), and have been limited to biochemical end points such as serum phosphorus, calcium, and PTH. In contrast, the sevelamer-versus-calcium 'treat-to-goal' study provided objective, serial measures of vascular calcification by EBT, in addition to longterm biochemical end points [18].

Calcium acetate is commonly used in the USA, while calcium carbonate is the predominant calcium-based phosphate binder used in Europe. Since calcium salts were found to be associated with progressive vascular calcification, and since the two calcium salts were pooled in the primary analyses, it was reasonable to query whether the specific binder might influence likelihood and extent of progressive calcification. Since calcium acetate has fewer milligrams of elemental calcium per tablet than calcium carbonate, one might hypothesize that the quantity of absorbed calcium ('calcium load') might be significantly lower in individuals taking the acetate preparation and that progressive calcification would be less likely.

Four randomized clinical trials have compared calcium acetate and calcium carbonate. Caravaca et al. [30] conducted a three-phase randomized open-label trial comparing calcium acetate and calcium carbonate in 80 maintenance hemodialysis patients. After a 2-week washout period (phase 1), the subjects were given $1.5 \mathrm{~g}$ of elemental calcium $(6.5 \mathrm{~g}$ calcium acetate and $3.75 \mathrm{~g}$ calcium carbonate) for 2 months (phase 2) and then underwent dose titration for 2 months (phase 3). Pooling the results from both active phases, there were no significant differences in serum phosphorus, calcium, or PTH. Ring et al. [31] conducted a 15-subject randomized double-blind crossover study (study duration 3 weeks). There were no significant differences in serum phosphorus, calcium, or PTH. Pflanz et al. [32] conducted a randomized unblinded crossover study (study duration 6 weeks) in 31 maintenance hemodialysis patients, comparing equimolar doses of calcium acetate and carbonate. These authors reported a lower end-of-study serum phosphorus concentration in the calcium-acetate-treated subjects as well as higher serum calcium concentrations and lower PTH levels, although their results were reported only for the 23 subjects who completed the protocol. Twice as many subjects were noncompliant with calcium acetate (18 vs. 9\%), and 4 subjects on calcium acetate dropped out due to side effects (as compared with 1 subject on calcium carbonate). Janssen et al. [33] randomized 53 hemodialysis

patients to aluminum hydroxide, calcium carbonate, and calcium acetate, and the subjects were followed for over 1 year (37 subjects completed the study). When comparing calcium salts, there was no significant difference in the end-of-study serum phosphorus or PTH concentrations. The incidence of hypercalcemia (defined as an albumincorrected serum calcium $>11.2 \mathrm{mg} / \mathrm{dl}$ ) was significantly higher in the calcium-carbonate-treated subjects (31 vs. $18 \%$ ). However, the calcium-acetate-treated subjects received significantly more adjuvant aluminum hydroxide (mean daily dose 1.29 vs. $0.69 \mathrm{~g}$ ) to optimize phosphorus control and to abrogate hypercalcemia. The dialysate calcium concentration used in this study was $3.5 \mathrm{mEq} / \mathrm{l}$. Finally, it should be noted that there was a marked difference in gender by calcium preparation (all 13 subjects who completed therapy with calcium carbonate were women as compared with 7 of 18 subjects who 
completed therapy with calcium acetate) that might have further confounded the results. Therefore, while advocates of calcium acetate have highlighted these and other single-meal metabolic studies $[17,18]$, there is little evidence for a material difference in safety or efficacy of one or another calcium-based phosphate binder.

This analysis of US subjects randomized to sevelamer or calcium acetate demonstrates that the use of calcium acetate is associated with progressive coronary artery and aortic calcifications. The increase in calcification cannot be blamed on inferior control of serum phosphorus or the calcium-phosphorus product or on the use of vitamin D or vitamin D analogs (which declined in the calcium-acetate-treated subjects). Moreover, the calcium-acetatetreated subjects were more likely to receive statins, also known to attenuate progressive coronary artery calcification [34]. Treatment with calcium acetate was associated with an increased incidence of hypercalcemia despite several provisions to abrogate elevations in serum calcium. Hypercalcemia has been previously associated with vascular calcification [35] and an increased risk of death [6].

The daily quantity of ingested elemental calcium (from calcium acetate) was $1.2 \pm 0.5 \mathrm{~g}$, less than the 1.5 -gram elemental calcium 'ceiling' recommended by the K/DOQI Clinical Practice Guidelines for Bone Metabolism and Disease and the $1.6 \pm 0.7 \mathrm{~g}$ ingested by the European study subjects taking calcium carbonate. Indeed, the dose of elemental calcium acetate ingested by the study subjects was modest when compared with other studies of calcium carbonate intake and vascular calcification. Goodman et al. [36] showed that the mean daily dose of calcium carbonate prescribed to adolescents and young adults with and without coronary artery calcification was 6,456 vs. $3,325 \mathrm{mg}$, corresponding to 2.6 versus $1.3 \mathrm{~g}$ elemental calcium $(p=0.02)$. In the study performed by Guérin et al. [35], the average doses of elemental calcium were $1.35,1.35,1.50,1.84$, and $2.18 \mathrm{~g} /$ day in subjects with $0,1,2,3$, or 4 sites of vascular calcification, as determined by B-mode ultrasonography $(\mathrm{p}=0.001)$. Therefore, the intake of calcium salts in excess of what can either be incorporated into bone or excreted into stool or urine (and not necessarily in doses many-fold higher) may be sufficient to promote vascular calcification. In vitro evidence suggests that hyperphosphatemia may potentiate these effects by inducing phenotypic transformation of vascular smooth muscle cells into cells capable of expressing osteoblastic activity [37, 38].

Sevelamer was associated with favorable effects on the lipid profile and on C-reactive protein, a proxy for inflammation. It is noteworthy that the change in C-reactive pro- tein was not associated with changes in LDL cholesterol. Other drugs that lower LDL cholesterol (HMG-CoA reductase inhibitors, 'statins') have been shown to have anti-inflammatory properties [39, 40]. More research will be required to determine whether sevelamer has independent anti-inflammatory effects in persons with kidney disease.

There are several limitations to this study. While a highly sensitive tool, EBT cannot differentiate intimal from medial calcifications. Therefore, we cannot determine whether sevelamer attenuates the progression of atherosclerosis or the progression of arteriosclerosis. While it can be argued that both should best be avoided, a better understanding of the mechanism of accelerated vascular calcification in end-stage renal disease and methods to interrupt these processes would be extremely valuable. Although the subjects in this study were randomized, we cannot determine whether the benefits afforded to those on sevelamer were related to differences in exogenous calcium, changes in bone dynamics, or alterations in lipids or inflammation, since the relative effects of sevelamer and calcium extend to each of these domains. These results may not be generalizable to typical clinical practice, where many patients may not receive the same degree of attention given to clinical trial participants and where protocols for provision of vitamin D analogs and other therapies may be less stringently followed. Indeed, the relative effects in less well monitored settings may be more pronounced. The results may not apply to patients on peritoneal, rather than to those on hemodialysis. Finally, while vascular calcification has been strongly associated with mortality in hemodialysis patients, additional studies will be required to confirm that preventing or attenuating the progression of vascular calcification decreases the mortality and the rates of cardiovascular, cerebral, and peripheral vascular events.

In summary, targeted therapy for hyperphosphatemia with calcium acetate led to a high incidence of hypercalcemia and progressive coronary artery and aortic calcifications. Sevelamer provided equivalent control of hyperphosphatemia with fewer adverse metabolic effects and attenuated the progression of vascular calcification. Sevelamer also yielded favorable effects on the lipid profile and may have had an anti-inflammatory effect. The potential risks and benefits of calcium acetate, like those of calcium carbonate, aluminum hydroxide, and other metal-based enterally absorbed phosphate binders, must be carefully considered. Exogenous calcium loading may contribute to the epidemic of vascular disease in hemodialysis patients. 


\section{References}

1 Indridason OS, Quarles LD: Hyperphosphatemia in end-stage renal disease. Adv Ren Replace Ther 2002;9:184-192.

2 Llach F, Velasquez Forero F: Secondary hyperparathyroidism in chronic renal failure: Pathogenic and clinical aspects. Am J Kidney Dis 2001;38(5 Suppl 5):20-33.

3 Locatelli F, Cannata-Andia JB, Drüke TB, Horl WH, Ritz E: Management of disturbances of calcium and phosphate metabolism in chronic renal insufficiency, with emphasis on the control of hyperphosphataemia. Nephrol Dial Transplant 2002;17:723-731.

4 De Boer IH, Gorodetskaya I, Young B, Hsu CY, Chertow GM: The severity of secondary hyperparathyroidism in chronic renal insufficiency is GFR-dependent, race-dependent, and associated with cardiovascular disease. J Am Soc Nephrol 2002;13:2762-2769.

5 Block GA, Hulbert-Shearon TE, Levin NW, Port FK: Association of serum phosphorus and calcium $\times$ phosphate product with mortality risk in chronic hemodialysis patients: A national study. Am J Kidney Dis 1998;31:607-617.

6 Lowrie EG, Lew NL: Death risk in hemodialysis patients: The predictive value of commonly measured variables and an evaluation of death rate differences between facilities. Am J Kidney Dis 1990;15:458-482.

7 Marchais SJ, Metivier F, Guérin AP, London GM: Association of hyperphosphataemia with haemodynamic disturbances in end-stage renal disease. Nephrol Dial Transplant 1999;14: 2178-2183.

8 Bardin T: Musculoskeletal manifestations of chronic renal failure. Curr Opin Rheumatol 2003;15:48-54.

9 Clarkson EM, McDonald SJ, de Wardener HE: The effect of a high intake of calcium carbonate in normal subjects and patients with chronic renal failure. Clin Sci 1966;30:425-438.

10 Slatopolsky E, Weerts C, Lopez-Hilker S, Norwood K, Zink M, Windus D, Delmez J: Calcium carbonate as a phosphate binder in patients with chronic renal failure undergoing dialysis. N Engl J Med 1986;315:157-161.

11 Mactier RA, Van Stone J, Cox A, Van Stone M, Twardowski Z: Calcium carbonate is an effective phosphate binder when dialysate calcium concentration is adjusted to control hypercalcemia. Clin Nephrol 1987;28:222-226.

12 Fournier A, Morinière $\mathrm{P}$, Ben Hamida F, el Esjer N, Shenovda M, Ghazali A, Bouzernidj M, Achard JM, Westeel PFl: Use of alkaline calcium salts as phosphate binder in uremic patients. Kidney Int Suppl 1992;38:50-61.

13 Malluche HH, Monier-Faugere MC: Hyperphosphatemia: Pharmacologic intervention yesterday, today and tomorrow. Clin Nephro 2000;54:309-317.
14 Saupe J, Belmega G, Krause R, Bennhold I: Management of hyperphosphatemia with calcium citrate in hemodialysis patients. Nephron 1989;52:93-94.

15 Emmett M, Sirmon MD, Kirkpatrick WG, Nolan CR, Schmitt GW, Cleveland MB: Calcium acetate control of serum phosphorus in hemodialysis patients. Am J Kidney Dis 1991;17: 544-550.

16 Bro S, Rasmussen RA, Handberg J, Olgaard K, Feldt-Rasmussen B: Randomized crossover study comparing the phosphate-binding efficacy of calcium ketoglutarate versus calcium carbonate in patients on chronic hemodialysis. Am J Kidney Dis 1998;31:257-262.

17 Birck R, Zimmermann E, Wassmer S, Nowack $\mathrm{R}$, van der Woude FJ: Calcium ketoglutarate versus calcium acetate for treatment of hyperphosphataemia in patients on maintenance haemodialysis: A cross-over study. Nephrol Dial Transplant 1999;14:1475-1479.

18 Chertow GM, Burke SK, Raggi P: Sevelamer attenuates the progression of coronary and aortic calcification in hemodialysis patients. Kidney Int 2002;62:245-252.

19 Sheikh MS, Maguire JA, Emmett M, Santa Ana CA, Nicar MJ, Schiller LR, Fordtran JS: Reduction of dietary phosphorus absorption by phosphorus binders: A theoretical, in vitro, and in vivo study. J Clin Invest 1989;83:66-73.

20 Mai ML, Emmett M, Sheikh MS, Santa Ana CA, Schiller LR, Fordtran JS: Calcium acetate, an effective phosphorus binder in patients with renal failure. Kidney Int 1989;36:690-695.

21 Canavese C, Bergamo D, Dib H, Bermond F, Burdese M: Calcium on trial: Beyond a reasonable doubt? Kidney Int 2003;63:381-382.

22 Fournier A, Benyahia M, Claudia CP, Sadek T: Calcium on trial: Beyond a reasonable doubt? Kidney Int 2003;63:382-383.

23 Cleveland M: Calcium on trial: Beyond a reasonable doubt? Kidney Int 2003;63:383.

24 Nolan CR, Quinibi WY: Calcium on trial: Beyond a reasonable doubt? Kidney Int 2003; 63:383.

25 Friedewald W, Levy R, Fredrickson D: Estimation of the concentration of low-density lipoprotein cholesterol in plasma, without use of the preparative ultracentrifuge. Clin Chem 1972;18:499-502.

26 Nauck M, Kramer-Guth A, Bartens W, Marz $\mathrm{W}$, Wieland $\mathrm{H}$, Wanner $\mathrm{C}$ : Is the determination of LDL cholesterol according to Friedewald accurate in CAPD and HD patients? Clin Nephrol 1996;46:319-325.

27 Achenbach S, Ropers D, Mohlenkamp S, Schmermund A, Muschiol G, Groth J, Kusus M, Regenfus M, Daniel WG, Erbel R, Moshage $\mathrm{W}$ : Variability of repeated coronary artery calcium measurements by electron beam tomography. Am J Cardiol 2001;87:210-213.

28 Agatston AS, Janowitz WR, Hildner FJ, Zusmer NR, Viamonte M Jr, Detrano R: Quantification of coronary artery calcium using ultrafast computed tomography. J Am Coll Cardiol 1990;15:827-832.
29 Raggi P, Boulay A, Chasan-Taber S, Amin N, Dillon M, Burke SK, Chertow GM: Cardiac calcification in adult hemodialysis patients: A link between end-stage renal disease and cardiovascular disease? J Am Coll Cardiol 2002 39:695-701.

30 Caravaca F, Santos I, Cubero JJ, Esparrago JF, Arrobas M, Pizarro JL, Robles R, Sanchez-Casado E: Calcium acetate versus calcium carbonate as phosphate binders in hemodialysis patients. Nephron 1992;60:423-427.

31 Ring T, Nielsen C, Andersen SP, Behrens JK Sodemann B, Kornerup HJ: Calcium acetate versus calcium carbonate as phosphorus binders in patients on chronic haemodialysis: A controlled study. Nephrol Dial Transplant 1993;8:341-346.

32 Pflanz S, Henderson IS, McElduff N, Jones $\mathrm{MC}$ : Calcium acetate versus calcium carbonate as phosphate-binding agents in chronic haemodialysis. Nephrol Dial Transplant 1994;9: 1121-1124

33 Janssen MJ, van der Kuy A, ter Wee PM, van Boven WP: Aluminum hydroxide, calcium carbonate and calcium acetate in chronic intermittent hemodialysis patients. Clin Nephrol 1996; 45:111-119.

34 Callister TQ, Raggi P, Cooil B, Lippolis NJ, Russo DJ: Effect of HMG-CoA reductase inhibitors on coronary artery disease as assessed by electron-beam computed tomography. N Engl J Med 1998;339:1972-1978.

35 Guérin AP, London GM, Marchais SJ, Metivier F: Arterial stiffening and vascular calcifications in end-stage renal disease. Nephrol Dial Transplant 2000;15:1014-1021.

36 Goodman WG, Goldin J, Kuizon BD, Yoon C, Gales B, Sider D, Wang Y, Chung J, Emerick A, Greaser L, Elashoff RM, Salusky IB: Coronary-artery calcification in young adults with end-stage renal disease who are undergoing dialysis. N Engl J Med 2000;342:1478-1483.

37 Giachelli CM, Jono S, Shioi A, Nishizawa Y, Mori K, Morii H: Vascular calcification and inorganic phosphate. Am J Kidney Dis 2001; 38(4 Suppl 1):34-37.

38 Jono S, McKee MD, Murry CE, Shioi A, Nishizawa Y, Mori K, Morii H, Giachelli CM: Phosphate regulation of vascular smooth muscle cell calcification. Circ Res 2000;87:E10-E17.

39 Undas A, Brozek J, Musial J: Anti-inflammatory and antithrombotic effects of statins in the management of coronary artery disease. Clin Lab 2002;48:287-296.

40 Ansell BJ, Watson KE, Weiss RE, Fonarow GC: hsCRP and HDL Effects of Statins Trial (CHEST): Rapid effect of statin therapy on Creactive protein and high-density lipoprotein levels. A clinical investigation. Heart Dis 2003; $5: 2-7$. 